\title{
Aproximación a la industria discográfica y su relación con la industria radial en Chile (1964-1967)
}

\author{
Claudio Gajardo Cornejo
}

Universidad de Chile, Santiago, Chile. Email: gajardocornejo@gmail.com

Resumen: Dentro del organigrama de la industria musical, las casas discográficas y emisoras radiales generan su dependiente relación por medio de la música grabada. En nuestro país, entre los años 1964-67, los sellos fonográficos nacionales lograron que muchos de sus artistas fueran invitados a las estaciones radiales por los disc-jockeys más famosos para promocionar sus discos. No obstante, se produjeron constantes discusiones y polémicas cuando las radios no difundieron, o bien, silenciaron muchos registros discográficos de intérpretes criollos, puesto que consideraron que las casas disqueras plasmaron mucha música que no merecía ser editada. Las emisoras radiales se defendieron argumentando que, prácticamente, no valía la pena ser dueño de un pequeño sello discográfico, ni invertir en promoción, ni conseguir discos de éxito cuando sus artistas no podían demostrar su talento en directo. En otras palabras, las radios chilenas exigieron calidad integral al artista nacional: hit radial y presentación en vivo.

Palabras claves: Sellos disqueros, productores, artistas, programadores, disc-jockeys.

\section{Approach to the discographic industry and its relationship with the radio industry in Chile (1964-1967)}

\begin{abstract}
Within the musical industry, record labels and radio stations generate their interdependent relationship through recorded music. In our country, between the years 1964-67, the national phonographic labels were able to have many of their artists invited to the different radio stations by the most famous DJs to promote their albums. However, constant discussions occured when radio stations did not broadcast or silenced several records of local interpreters, arguing that many companies recorded music not worth being edited. The radio stations defended themselves arguing that it was not worth the effort of owning a small record label, or invest in promotion, or achieve hit records, when their artists could not demonstrate their talent on live shows. In other words, radios demanded integral quality to national artists: radio hits and alive performances.
\end{abstract}

Key words: Record labels, producers, artists, programmers, disc-jockeys.

\section{Abordagem à indústria da música e sua relação com o setor de rádio no Chile (1964-1967)}

Resumo: Dentro da organização da indústria da música, gravadoras e emissoras de rádio geram uma relação de dependência com a música gravada. Em 
nosso país, entre os anos 1964-67, os selos fonográficos nacionais para muitos de seus artistas foram convidados para as estações de rádio, os DJs mais famosos para promover os seus álbuns. No entanto, havia discussões e debates, quando as rádios não transmitem, ou silenciam muitas gravações de intérpretes nacionais, uma vez que consideraram que muitas gravadoras gravaram registros que não mereceram ser editados. As estações de rádio tinham defendido argumentando que, praticamente, não valia a pena possuir uma gravadora pequena, ou investir em promoção, ou obter registros de sucesso quando seus artistas, não puderam mostrar seu talento ao vivo. Em outras palavras, as rádios exigiram da integrante artista nacional chileno: hit de rádio e performances ao vivo.

Palavras-chave: gravadoras, produtores, artistas, programadores, DJ's.

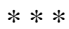

\section{Introducción}

La industria cultural es una organización compleja que trabaja creando, regulando, así como distribuyendo mercancías o productos culturales. Como bien sabemos, dicha industria trabaja, en beneficio propio, y sólo busca su rentabilidad económica, no importando si sus planes de trabajos resultan ser convenientes para la educación, o bien, para la cultura de una sociedad. Su ideología está modelada por una política capitalista que adquiere una actitud burocrática y, por medio de ella, pasan las decisiones finales, en cuanto a la forma y fondo de sus mismos productos culturales.

No olvidemos que la industria musical que produce, distribuye y comercializa música grabada tiene el mismo fin que la industria cultural: la venta masiva. Juan Pablo González y Claudio Rolle; en su libro, Historia Social de la Música Popular en Chile, 1890-1950; señalan que la industria musical consigue su funcionamiento cuando existe un público grande que se convierte más en consumidor que en productor, así como cuando fabrica ofertas musicales permanentes y contingentes a las sociedades modernas (González y Rolle 2005: 174) ${ }^{1}$.

De este modo, la industria musical se vincula con la categoría comercial de la música para hacer de ésta una mercancía cultural amplia. Para ello, trabaja con un comité creativo y colectivo de productores, creadores, autores, compositores, dueños de sellos discográficos, entre otros, que estudian y analizan los planes de trabajos que permitan alcanzar su éxito lucrativo en el consumo de masas. La industria musical y cultural labora como una gran maquinaria que maneja las conciencias e inconsciencias de la sociedad y mantiene una estrecha relación con la cultura de masas. Edgar Morin y Theodor W. Adorno; enuncian, en su publicación, La Industria Cultural; que dicha cultura se entiende como:

"una cultura que surge espontáneamente de las propias masas, en suma, de la forma actual del arte popular“. (Morin y Adorno 1967: 9).

La investigadora colombiana, Diana Gutiérrez Toro, en su Tesis de Magíster en Artes con mención en Musicología, La Música como Antídoto 
de la imagen: El caso "Blue”, admite que la cultura de masas se señala entonces, como aquella que se caracteriza por un patrón o modelo de gusto social-mayoritario:

"La cultura de masas es inevitable y significa una amplia estandarización del gusto y de la capacidad de recreación. A pesar de las múltiples ofertas, el consumidor sólo tiene una libertad de elección que es aparente. [...] La cultura de masas es asumida no sólo como un conjunto de objetos culturales, sino también como un conjunto de comportamientos operantes. El éxito de la cultura de masas, opina Rositi ${ }^{2}$, está en su carácter de ser asimilable a un proceso de interiorización y a una necesidad colectiva de esparcimiento y de resarcimiento psicológico”. (Gutiérrez Toro 2003: 40 y 44).

Como bien enunciamos, un comité creativo y colectivo de la industria musical proyecta, minuciosamente, sus estrategias y se mantiene en continua actividad para el mencionado consumo de masas. Así, toma en cuenta la fabricación, producción, distribución e, incluso, estudios de mercado que determinan el éxito de aquella campaña. Los métodos estratégicos de servicios de la industria musical y cultural apuntan a que el consumidor no logra actuar como el sujeto, sino que como el objeto. Morin y Adorno no exageran cuando declaran que dichas organizaciones, de alguna manera, tienden a imponer los destinos de la sociedad a su propio fin consumista: propósito que somete al mismo individuo a su conformismo. Un conformismo que actuaría, sólo pensando en sus propios intereses egoístas. (Morin y Adorno 1967: 9-38).

La producción de materia prima, mercancía o producto cultural puede ser de origen nacional y/o trasnacional y toma, en cuenta, la creación de canciones de éxitos, así como modas socio-musicales que son impulsadas e ideadas muchas veces desde los propios centros de la industria musical. Cabe señalar que muchos intérpretes contratados por la referida organización son recogidos y, en ocasiones, adecuados para su registro y difusión. $\mathrm{La}$ industria musical selecciona a las obras que circulan en el mercado, impone un cierto criterio sobre los procesos de creación musical y fabrica un público que está dispuesto a consumirla ${ }^{3}$.

El sello discográfico es la empresa que se responsabiliza por la edición, comercialización y distribución de la música grabada de sus artistas para los distintos medios de comunicación. Las casas disqueras se encargan que el indicado material sea analizado por publicistas y personas especializadas, en marketing, quienes velarán cómo, dónde, cuándo y por qué deberá ser lanzado dicho disco. No hay que olvidar que el público receptor es estudiado con minuciosidad y aquello implica cuál sector de la sociedad le será dirigida la aludida mercancía musical. El sello discográfico, se divide por medio de secciones que funcionan como una empresa artística y cuenta, además, con departamentos medulares como, producción, publicidad, el citado marketing, relaciones públicas, etc. Asimismo, resulta necesario añadir que las compañías disqueras son compradas por otras más gran- 
des cuando ambas logran establecer un mutuo acuerdo económico.

Por otro lado, la radio es el medio de comunicación que juega un cuádruple papel dentro de la industria cultural y musical, puesto que además de efectuar actividades como informar, comentar y ofrecer publicidad, también difunde música ${ }^{4}$. El desaparecido crítico musical y compositor, Domingo Santa Cruz, definió a la radio como el descubrimiento más extraordinario desde la imprenta. Así, valora su invención cuando redactó la columna, Medio Siglo, para la Revista Musical Chilena:

"La radio, es sin lugar a dudas, el descubrimiento más milagroso que se ha hecho desde que la imprenta fue conocida en el mundo occidental. Participa de la comunicatividad de la imprenta, con la ventaja que el libro maravilloso de la radio lo puede abrir cualquier individuo, aun el analfabeto; basta con accionar los controles para que en nuestra casa, en la casa de cualquiera, se oigan todas las voces del espacio, aun las que vienen del extranjero. [...] La radio como medio de comunicación, aventaja al teléfono, aventaja al telégrafo y los supera en que ya no hay distancias y en que no existen medios materiales que se interpongan. No podemos hablar, es cierto, no podemos contradecir, sólo podemos escuchar y cuando algo nos fastidia, dejamos de oír. Es una voz docente que se entra por todas partes, que se oye por las calles y que sólo podemos cambiar por otra voz, por otro maestro, porque la palabra puede alcanzar ${ }^{5}$ ". (Santa Cruz; RMCH 37; 1950: 7-8)

Las emisoras radiales integran, en sus equipos de trabajos, a dos actores muy relevantes como son el programador radial y el disc-jockey. La labor del programador radial consiste en popularizar las canciones que más aprecia, según su criterio, y otorga la línea musical de su estación radial. En tanto, el disc-jockey es el personaje que posee un espacio y un público que le solicita piezas musicales a una hora determinada. Se crean conversaciones e interacciones entre el oyente y el disc-jockey en torno a un ámbito y logra hacerse "popular" cuando encuentra empatía con un público radial que lo llama, o bien, le escribe cartas para concursar en el ranking radial de las mejores canciones de la semana.

En consecuencia, el programador radial y el disc-jockey ${ }^{6}$ se transforman no tan sólo en los descubridores y propulsores de muchos artistas, sino que también en sus "silenciadores" cuando deciden qué piezas musicales merecen o no ser circuladas.

\section{Desarrollo}

\section{Las políticas de los sellos discográficos en Chile (1964-1967)}

Entre 1964-1967, en Chile, no era difícil instituir una casa discográfica debido a que se contaba con el apoyo de las grandes compa- 
ñías internacionales residentes: RCA Víctor y ODEON. Sin embargo, pese a que la industria fonográfica criolla y su duplicación técnica se inclinó a un crecimiento, nunca alcanzó a ser un punto central ni menos que fuera más relevante que el resto del continente.

El artículo de El Musiquero, Hablemos de los sellos particulares, reveló que a pesar de que las casas discográficas experimentaron altos costos de registros fonográficos, en nuestra nación existió una gran demanda de compra de discos de intérpretes favoritos. Del mismo modo, la citada columna indicó que, a mediados de los años ‘ 60 , alguien podía pasar de ser productor independiente a convertirse en dueño de una propia casa discográfica. Lo anterior explica, entonces, las ganancias económicas de directores artísticos como Camilo Fernández y cómo logró que su exitoso proyecto fuera imitado por otros, aunque, ciertamente, con distintos resultados. En síntesis, la supervivencia de los sellos disqueros criollos se plasmó en sólo aquellos que manejaron políticas adecuadas de captura de más clientes. (El Musiquero. No. 45, agosto de 1967: 7).

En otros países, las casas disqueras que obtenían grandes ingresos compraban máquinas y se interesaron en su respectiva economía nacional. No obstante, en nuestro país, hubo discusiones, en torno al tema, porque el mercado era muy exiguo para tantos sellos discográficos y, peor aún, no todos poseían la agudeza empresarial de Fernández para mantenerse. ¿¿La razón? Varias casas fonográficas criollas "malgastaron” sus ganancias en vez de invertirlas para otros efectos.

No tan sólo los dueños de las pequeñas casas disqueras reunieron grandes sumas de dinero para la difusión de los discos grabados de sus artistas, sino que, además, debieron capitalizar en su promoción. Para 1967, el dueño de una pequeña casa discográfica, que pretendió aventurarse en el enunciado negocio musical, debía tener enormes recursos monetarios para invertir en grabación. Luego, esperaba que las multinacionales como el Sello RCA Víctor o Sello ODEON editaran los discos de los nuevos intérpretes para publicarlos y comenzar la anhelada difusión. El musicólogo Jorge Martínez Ulloa en su escrito, La década de los '60 y la música de difusión masiva: la Nueva Ola Chilena como sistema cultural; señala que los proyectos de publicidad o campañas publicitarias tuvieron un costo económico que resultó ser un tanto formal como informal:

“Una vez hecho el 'master', las 'majors' procedían al[a] duplicación de cada disco, lo lanzaban a la venta y efectuaban parte de la promoción. Cuando salía el disco al mercado, el propietario del sello se preocupaba de organizar una campaña de prensa, con entrevistas a los artistas de los dj más afamados, artículos de prensa y publicaciones en revistas especializadas. Todo ello tenía un costo, a veces formal, otras informal“. (Martínez Ulloa 2000: 10-11).

En el siguiente párrafo, analizaremos cómo El Musiquero se contrapuso al entusiasmo de los propietarios de las compañías discográficas crio- 
llas que contrataron a intérpretes que sólo "gritaban" en vez de cantar. ¿Una alusión, quizás, a prototipos de artistas de la Nueva Ola, o bien, del Beat Chileno como Los Pussycats o Los Mendigos, respectivamente, que grabaron para el Sello ORPAL y que no tuvieron ninguna posibilidad de pertenecer al staff de sellos multinacionales?:

\begin{abstract}
“[...] el candidato a propietario, debe tener un capital considerable, porque debe pagar de su bolsillo, todos los gastos de grabación, lo que suma, generalmente, por cada disco ' 45 ', no menos de unos dos mil escudos. Una vez realizada la grabación, la industria, llámese RCA Víctor u ODEON (las dos únicas industrias reales en Chile) prensan el disco, lo lanzan a la venta y efectúan parte de la llamada promoción. Cuando aparece el disco, es cuando el propietario del sello, se lanza desesperado a las radios, a los diarios y a las revistas en busca de apoyo. Descubre entonces, ante la indiferencia de la mayoría, que todo no estaba tan bien, y que el 'astro’ que él descubriera no era tal, que la orquestación, no era totalmente lograda, y así, una serie de detalles, que significan pérdidas de materiales, pérdidas morales y que fundamentalmente le dicen al candidato a propietario, que sus conocimientos no llegaban a la altura de su entusiasmo. Se podría decir a esas alturas, que si el perjudicado es el que desea tener el sello, por qué causa nosotros estimamos peligrosa la proliferación de este tipo de discos. Y es, justamente por todo eso ${ }^{7}$ ”. (El Musiquero, No. 45, agosto de 1967: 7).
\end{abstract}

Los grandes sellos multinacionales como RCA Víctor y ODEON siguieron patrocinando a las casas disqueras criollas para que contrataran a todo tipo de intérpretes con sólo desembolsar unos cuantos billetes para su gestión. Sin embargo, si se piensa que fue fácil la tarea para las compañías nacionales, lo cierto es que éstas se vieron perjudicadas cuando sus artistas no lograron comercializar sus discos. De este modo, la mayoría de los dueños de sellos discográficos criollos culpó a la real indiferencia de las radioemisoras, así como a los disc-jockeys cuando se resistieron a publicitar a ciertos intérpretes. No obstante, los trabajadores radiales se defendieron cuando denunciaron la exagerada propuesta de dichos directores que contrataron, a muchos artistas, para que plasmaran registros fonográficos. ¿El problema? No hubo una pertinente ni rigurosa selección:

"Para llegar a hacer discos de éxito, no basta tener amigos en la radio, o en la prensa. No es suficiente ser músico, ni mucho menos tener condiciones notables como autor. Nada de eso sirve a la postre. Cada nuevo sello que nace en estas condiciones, generalmente está condenado al fracaso. Y junto con su fracaso, lo harán artistas, compositores y todo lo que mueve tras esa industria. Estimamos indispensable, una justa revisión de esta política de apadrinar sellos particulares, por parte de las casas grabadoras. De continuar en las actuales circunstancias, día a día cundirán el mal gusto, el ruido y los malos artistas que muchas veces, en plan de grabar, son capaces incluso de costear de su bolsillo, la grabación de un par de temas ${ }^{8}$. 
Sinceramente, estimamos que se le hace un flaco servicio a la música popular ${ }^{9}$. (El Musiquero. No. 45, agosto de 1967: 7).

En el período referido, existían, además del _ LP, dos tipos de discos de vinilo como el single (45 r.p.m.) y el long play (33 1/3 r.p.m). Estos tres formatos eran comercializados por los sellos discográficos y revistas como El Musiquero le otorgaron, al disco, el valor similar al de un libro. Así, en su formato single y long play, dicho medio escrito motivó, a sus lectores, a adquirirlos y, más aún, cuando las casas disqueras acordaron de ajustar sus precios con el fin de que se siguiera difundiendo la música. Por ello, la mencionada revista, en su crónica, Hablemos de..., argumentó que el disco era "esencialmente, un vehículo educativo [apreciable] e indispensable en la marcha cultural de una nación”. (El Musiquero. No. 20, 1ª . Quincena de agosto de 1965: 3).

El Musiquero, en su afán de explicar, detalladamente, sobre el funcionamiento interno de los sellos discográficos, indicó que el precio que los consumidores pagaban por un disco incluía, tanto la impresión de etiquetas o carátulas como los derechos de autor, interpretación, dirección, etc. La pronunciada explicación guardó relación con hacer comprender que si bien, en una época, los montos de los discos bajaban, y luego, volvían a subir, no era por mero capricho, sino, más bien, por diversos costos que las referidas empresas no podían ignorar. No obstante, el enunciado medio escrito veía con optimismo que, en la actualidad, el público estaba respondiendo a la compra de discos. (El Musiquero. No. 20, $1^{\text {a }}$. Quincena de agosto de 1965: 3).

A fines de 1964, hubo una gran diferenciación de precios de registros discográficos y la discusión se tornó bien conflictiva cuando, repentinamente, se bajaron los montos. La crónica que el columnista, CAVE, redactó para El Musiquero, Hablemos de... discos a menor costo, cuestionó tal procedimiento cuando no se hizo tal operación anteriormente. De la mencionada problemática, surgió la información de que algunas producciones eran más costosas que otras cuando, por un lado, una orquesta y, por otro, un conjunto popular registraban su música. El conflicto no convergió con el estrato musical ni menos con la calidad de los músicos, sino, más bien, con la cantidad y el tiempo que cada propuesta demoraba en grabar. Por ende, a mayor tiempo en el estudio, mayor costo de grabación. Asimismo, las casas fonográficas conscientes de esta situación también comprendieron que los músicos de orquestas cobraban por precio fijo, además, de los costos que significaba cancelarles a compositores e intérpretes (CAVE, El Musiquero. No. 10, enero de 1965: 3). En consecuencia, la interrogante se esbozó de la siguiente manera: ¿deberían valer lo mismo las producciones musicales, tanto de orquestas como de cuartetos profesionales?

No obstante, el enunciado problema se hizo solucionable cuando, en nuestro país, las compañías discográficas prensaron los discos de artistas extranjeros, cancelando un cierto porcentaje a los sellos disqueros foráneos. Así, se comprendió que los excedentes que arrojaron materiales 
fonográficos de conjuntos como The Beatles o de cantantes como Elvis Presley significaron grandes ganancias para sellos como ODEON y RCA Víctor, respectivamente. Por tanto, aquellas ventas gestionarían recursos para plasmar producciones carísimas como El Mago Musical o Baile de Etiqueta (CAVE, El Musiquero. No. 10, enero de 1965: 3). De este modo, volviendo a la problemática planteada, ¿por qué las casas discográficas estuvieron bajando los precios de venta de sus producciones, si con esto último no estaban generando mayores recursos económicos para costear las mencionadas obras para orquesta?

Se comprendía que para pagar una producción orquestal se necesitaba vender cerca de 3000 discos. No obstante, sólo se comercializaban unidades cercanas a las 500 placas. Entonces, la evidente interrogante recayó, nuevamente, en el ¿por qué ciertas casas discográficas invirtieron en tales producciones si sólo engendraban pérdidas? CAVE tuvo una hipotética respuesta: así como los sellos discográficos generaron excedentes comerciales, también tuvieron una cuota de protección ante ciertas interpretaciones de músicos nacionales que requirieron de mayor paciencia, disciplina y rigurosidad en el estudio de grabación:

"Todos los discos de este tipo tienen costos tan altos, que necesitarían ventas superiores a las 3.000 unidades, al precio de 18 escudos, para costearse. Si pensamos que el índice medio de ventas de un disco L.P. es el orden de las 500 unidades, no hay que sacar muchas cuentas para ver que no son, precisamente, brillantes inversiones. ¿Qué por qué se hacen, piensa usted, lector? Por una causa simple: son discos que reflejan una línea musical chilena, una forma de creación que no puede quedar ahondada a su suerte, y que alguien tiene que proteger. En suma, el público tiene ahora mayor variedad a diferentes precios, al paso que la industria grabadora tiene por delante un panorama que no es precisamente brillante, y en el que tendrá que caminar con paso cuidadoso para no ver afectados sus intereses. Ojalá los que gustan de los discos, comprendan el esfuerzo [,] colaboren con quienes los fabrican, para conseguir un mercado estable y en alza ${ }^{10}$ ". (CAVE, El Musiquero. No. 10, enero de 1965: 3).

La inversión monetaria de obras conceptuales dio pie para que algunos directores artísticos de los sellos multinacionales protegieran a ciertas producciones nacionales, sobretodo, cuando constituyeron novedad, o bien, algún valor creativo. Aquello explica, entonces, el esfuerzo económico que representó para casas disqueras como RCA Víctor, la publicación de obras musicales como Al $7^{\circ}$ de Línea (1966) de Los Cuatro Cuartos, o bien, Kaleidoscope Men (1967) de Los Mac's. La anterior producción, gloriosa obra del Neo Folklore, significó exportar un long play que sintetiza un hecho histórico nacional-internacional como la Guerra del Pacífico, en tanto, la última, magnánima producción del Beat Progresivo-Psicodélico Chileno ${ }^{11}$, registra la vanguardia y novedad por medio de efectos especiales y extraños dentro de una base rockera ${ }^{12}$. 
Si bien, las compañías discográficas disminuyeron los precios de discos para su mayor comercialización, más tarde, las ventas de dichos materiales fonográficos, de igual forma, declinaron por dos factores: su encarecimiento debido al aumento de costos de todo orden y la preferencia dogmática que los programadores y disc-jockeys mantuvieron hacia ciertos discos. En el siguiente punto, trataremos esta última causal cuando le originó, a la industria musical chilena, ciertos trastornos entre 1964 y 1967.

\section{Las políticas de los disc-jockeys y programadores radiales (1964-1967)}

Analizando el rol de la radio en la sociedad urbana criolla entre 1964-1967, nos daremos por entendidos que nuestras emisoras entraron, a un juicio público, cuando se discutió que se parecían, en la programación, en el color vocal de sus locutores, así como en los temas sociales que abordaban. Vale decir, se les acusó que todas estaban siendo estandarizadas. Una investigación que analizó tal problemática fue profundizada por Ecran por medio del reportaje, Todas las emisoras se parecen, ¿Por qué?:

“Antes se dedicaba a la música clásica y ligera al estilo de Radio Andrés Bello, y ahora concentra su máximo interés en los discos de moda. Es probable que sean importantes las razones (búsqueda de una popularidad inmediata, economía de gastos, etc.) que han conducido a las emisoras al camino fácil de tocar discos tras disco. Pero ¿no habrá en esto un buen porcentaje de exageración? Planteadas así la situación de las radios porteñas (que no difieren mucho de la mayoría de las de Santiago), quedaba por averiguar las causas de ese cambio hacia ‘el camino fácil’”. (Ecran. No. 1740, 2 de junio de 1964: 5).

El disc-jockey chileno fue el personaje más relevante de la emisora radial durante los años ' 60 , luego de ganar prestigio y espacio en las voces de Raúl Matas, Ricardo García, Agustín Cucho Fernández, Juan Carlos Gil, Miguel Davagnino, José María Palacios, Julio Gutiérrez, Carlos Alfonso Hidalgo, Agustín Inostroza o el mismo Camilo Fernández. Tanto ellos como otros que laboraron, en varios puntos geográficos de nuestro país, fueron responsables de difundir sus temas musicales preferidos, así como los gustos de un público que solicitó la programación de discos de sus ídolos, tanto por vía telefónica como por correo ${ }^{13}$.

El disc-jockey fue un líder de opinión que logró, por medio de su estilo, determinar el éxito o fracaso de sus programas y, por ello, le permitió, en algunos casos, ganar más dinero que el propio Presidente de la República (Ecran, No. 1769, 22 de diciembre de 1964: 45). Por tal razón económica, ciertos medios escritos les exigieron que fuesen más responsables a la hora de mejorar el nivel cultural y técnico de la radiodifusión ${ }^{14}$. En los años ‘60, la fortuna o desgracia que podía tener la canción de un artista chileno pasaba por la sentencia del disc-jockey. Por tal razón, muchos personajes del nuestro medio se sumaron para alabar o criticar la labor de estos promotores de discos. En consecuencia, estos pinchadiscos fueron 
uno de los grandes orientadores de la música internacional, así como los principales responsables en la promoción del naciente y pujante movimiento artístico criollo ${ }^{15}$. Asimismo, otros disc-jockeys fueron activos productores de shows, festivales, giras y todo tipo de eventos, en apoyo de la música chilena y, en particular, de los intérpretes de la Nueva Ola ${ }^{16}$. (Martínez Ulloa 2000: 18).

La figura del disc-jockey se tornó crucial para las pretensiones de difusión de la música popular criolla, puesto que, por sus manos, pasaron las decisiones finales de lo que, radialmente, se escuchó, en nuestro país. Martínez Ulloa añade que si bien los disc-jockeys trabajaron con música y tiempo establecido, las elecciones musicales del programador radial fueron punto de reproches, por parte de medios críticos:

“Otra figura importante en las radioemisoras era el programador, muy criticado por sus elecciones y sus dopajes musicales, fue el blanco de las diatribas de la prensa especializada, en mayor medida del DJ, ya que éste imponía una línea más o menos definida en su programa y de todas formas, estaba presente en múltiples actividades y espacios relacionados con la música, en tanto que aquel se convirtió en el símbolo de la selección musical por la sintonía. El programador era el blanco de las críticas más feroces” (Martínez Ulloa 2000: 19).

Se consideraba que el disc-jockey o locutor dirigía una línea definida, en sus espacios radiales, mientras que el programador radial seleccionaba toda la música de la emisora para lograr mayor sintonía. El rol de este último fue definido, irónicamente, como un personaje que debía tener mucho conocimiento musical para apostar, finalmente, a la decisión de difundir, redundantemente, sólo treinta piezas musicales. Así, El Musiquero publicó la columna, Sin carátula: los programadores, para atacar contra todo programador radial que obtuvo mayor sintonía radial por medio de la repetición de treinta canciones durante todo el día:

“[El programador radial] tiene que saber la teoría famosa de los 30 discos que inventó un tarado en alguna parte y que sostiene que la mejor forma de ganar sintonía, es programando no más de 30 títulos durante un día, en forma repetida, y por un plazo total que pueda alargarse hasta los 10 años. [...] Debe dominar las matemáticas como cualquier DJ”. (El Musiquero. No. 47, octubre de 1967: 10).

Como podemos darnos cuenta, la sintonía radial “cegó” a muchos programadores que fueron en busca de mayor audiencia por medio de estrategias baratas, en vez de educar, musicalmente, al auditor. En otras palabras, los aludidos "trabajadores de radio" se ajustaron a las normas de estandarización de la industria cultural:

“Por ningún motivo debe gustar de la música clásica, mucho menos, de la música suave y agradable. El que haga programas así, 
entraña el riesgo de que el público los sintonice, que guste de ese música y que se vaya al diablo la sintonía de todas las demás emisoras. Es muy útil tener muy mal oído. Así, las desafinaciones, gritos y estridencias no las escuchan y programa con entusiasmo a todos los malos coléricos de la actualidad. Si Ud. reúne todas estas condiciones, ofrézcase como programador de una emisora, y si le falle, trate de convertirse en director artístico o de sacar su sello propio. Le va a ir bien”. (El Musiquero. No. 47, octubre de 1967: 10).

En el siguiente párrafo, Ruperto Vergara, ex-dueño de Radio Santiago, declaró que, en sus programaciones, utilizaba la difusión de discos comerciales, justificando que ignoraba que las otras emisoras harían lo mismo para ganar mayor sintonía. Asimismo, añadió que pese al valor que tenía la música clásica y de haber contado con los mejores elementos profesionales y genuinos como el desaparecido, Jorge Dahm, se tuvo que deshacer de este mismo cuando los resultados de las encuestas indicaban que casi no tenía auditores:

"En primer lugar fuimos los primeros en Radio Santiago en iniciar esa línea de bloque con discos. No imaginamos que todas las emisoras iban a hacer otro tanto. En mi radio tengo al mejor personal pagado del ambiente: eso significa que trabajan bien y explica nuestro éxito. A través de los discos hemos influido en crear el nuevo semillero de cantantes nacionales que hoy actúan y prosperan en todas las radios llamadas 'grandes'. Claro que también hemos perdido gente y programas. Desde luego a Jorge Dahm, para mí, el hombre más completo de la radiotelefonía. Pero sus programas clásicos, literarios, serios- no consiguen auditores. Sí, estoy contento, en cuanto a que la línea de Radio Santiago se hace con los mejores elementos: porque soy radiodifusor viejo y quisiera dejar algo más positivo, realizarme mejor”. (Vergara, Ecran. No. 1740, 2 de junio de 1964: 5).

¿Culpa o responsabilidad? Pese a que estos reproches malintencionados, sobre la insistencia de las mismas piezas musicales repetidas, se dirigieron hacia el programador, no toda la culpa la tendría este último en su proceder. ¿El por qué? Igualmente, habría compromiso compartido, por parte de los radioescuchas, que privilegiaron aquellos éxitos del momento. Así, hubo ciertos críticos de espectáculos que no comprendieron cómo, en Chile, se podía editar hasta casi siete versiones de un mismo tema musical, a razón de que el público los retuviera en su memoria auditiva (El Musiquero, no. 47, octubre de 1967: 10). No obstante, hubo una insolvencia por parte de los medios radiales en la creación de más espacios democráticos que puntualizaran los distintos gustos de la audiencia. El Musiquero trató tal problemática en su crónica, Editorial:

“Las programaciones de las emisoras, en una carrera que vale la pena analizar [...] han conseguido marcar una notoria sintonía para algunos discos, y al mismo tiempo no dan cabida a muchos otros, 
por razones de espacio y tiempo. Si nos detenemos a pensar que todas las industrias lanzan al mercado aproximadamente un centenar de discos o más al mes, o sea, más de doscientos títulos, y que en los programas sólo se oyen, repetidamente, varias veces al día, no más de cincuenta, tenemos que concluir que se están perdiendo mensualmente, por lo menos cien o ciento cincuenta títulos que el público prácticamente no conoce a través de la radio. Es indiscutible, desde el punto de vista comercial que los programadores que cada emisora mantiene, tienen la obligación de satisfacer a sus oyentes. Estos, por medio de cartas, marcan sus preferencias y los programadores les dan en el gusto y tocan y tocan los mismos discos, todos los días. ¿Es esta una política acertada? ${ }^{17}$ ” (El Musiquero. No. 5, agosto de 1964: 3).

El citado medio escrito manifestó su gran preocupación frente a la majadería de algunos programadores cuando consintieron, a su público, con la pronunciada repetición de ciertas canciones. ¿Consecuencias? El "silencio" del resto de los trabajos fonográficos que representaban el no despreciable promedio de un 60\%, o bien, $70 \%$ de su fabricación mensual. En otras palabras, una cifra no menor:

"Insistimos que si las emisoras quieren marcar sintonía, dando gusto a su público, evidentemente, lo es, pero ¿el esfuerzo de todos aquellos que han pasado inadvertidos con sus grabaciones, puede perderse, así como así? Autores, intérpretes, orquestadores, técnicos, etc, todos ven naufragar muchas ilusiones, ante el desconocimiento de sus creaciones a través del éter. Además, la industria del disco, en general, sufre también perjuicios evidentes, porque el exceso de ejecuciones de un mismo tema, varias veces al día, en todas las radios, resta interés al público comprador para incluir la grabación en su discoteca, ya que con solo sintonizar cualquier emisora, encuentra el o los temas de moda que actualmente podrían llamarse Best-Sellers, y que ahora escasamente podrían llamarse 'BestPlayed'. Tenemos, entonces, que nos encontramos frente a un cambio notorio del gusto del auditor, orientado por las emisoras, y ante una programación por parte de éstas, recargada a determinados temas, que produce un desconocimiento del 60 o $70 \%$ de la producción mensual de las empresas de discos ${ }^{18}$ ". (El Musiquero. No. 5, agosto de 1964: 3).

En su afán de generar conciencia a los programadores radiales, El Musiquero entendía que el negocio de la industria musical chilena tenía que basarse en un ideal equilibrado entre lo comercial y lo creativo para no “pasar a llevar” a tantos autores, compositores, intérpretes, productores y otros trabajadores de la industria discográfica que también tenían ilusiones de dar a conocer sus obras:

"Puede argumentarse que todos los discos se tocan, y que sólo se repiten los que el público pide, pero no hay duda que, por lo gene- 
ral, éste se interesa en un tema, recién cuando lo ha oído varias veces. Sinceramente, nos parece que es hora de meditar fríamente estos aspectos y construir sobre ellos. Un poco más de esto, y un poco menos de lo otro, y al final ganarán radioemisoras, público, industrias y básicamente, autores e intérpretes, que tienen derecho a un trato igualitario para sus creaciones frente a la totalidad de los discos que aparecen mensualmente ${ }^{19}$ ". (El Musiquero. No. 5, agosto de 1964: 3).

En la crónica, Sin carátula, de la referida revista, nuevamente, los dardos apuntaron, tanto al disc-jockey como al programador radial de ser los responsables de convertir, en astros, a ciertos artistas, así como de llevar, a otros, al absoluto fracaso. Aquí, se puso en discusión si la exagerada difusión radial de un material discográfico lograba el efecto, en el auditor, de querer comprarlo. Por ende, dicho artículo tomó, en consideración, una dicotomía que confluyó entre los discos que más se promocionaban versus los que más se comercializaban:

"Quiero hablar de los discos que se tocan y de los discos que se venden. Aparentemente, hay una total disimilitud de opiniones al respecto. Para otros, es más importante que se vendan. Lo primero es fácil. Sólo se necesita ser amigo de algunos DJ importantes, atenderlos regiamente y fregarlos durante todo el día para que toquen tal o cual disco. Lo segundo, es difícil. Es fundamental hacer buenos discos y después, tener un equipo de vendedores capaz de vender desde una caja de fósforo hasta un Cadillac. Ahora, ¿cuál disco se vende más? ¿El que se toca más o no? ¡Vaya pregunta! Hace más o menos unos cincuenta años, que la gente se pregunta lo mismo. Por mi parte, con la experiencia que tengo al respecto, (alrededor de veinte años) puedo informar que a la fecha, no sé. Es decir, estoy exactamente en el mismo plano que algunos Jefes de Promoción, Directores artísticos y otras yerbas, que tampoco saben de qué trata. Algunos han tratado de establecer una mecánica al respecto: Hacen tocar los discos como condenados, crean interés en el público, pero lo hacen con tanto interés, que el disco se toca alrededor de unas mil veces diarias y cuando sale a la venta, nadie quiere comprarlo y todos están aburridos con él ${ }^{20}$. Otros, lo hacen a la inversa. No envían el disco a las radios, no mandan párrafos a los diarios, no invitan a almorzar o a tomar cocteles a los amigos y el disco -por lógica- no se toca. Ambos obtienen lo mismo: Bajas ventas. ¿Cuál es, entonces, el punto exacto? Difícil sería decirlo, porque a la fecha, es inexplicable que 'El Pobre Pollo' siga siendo récord de ventas en Chile y que discos más tocados que 'La Cumparsita' (que ya no se vende hace unos diez años por lo menos), estén durmiendo en las bodegas del sueño de los 'promovidos ${ }^{21}$ '”. (El Musiquero. No. 32, agosto de 1966: 4).

El Musiquero definió el tipo de emisoras que existían en nuestro país: las que promocionaban las mismas treinta piezas musicales todos los 
días, las que daban a conocer exclusividades y las que difundían todo el material fonográfico que tenían. En consecuencia, frente a esta consecuencia generada por la selección musical de disc-jockeys y programadores se originaba el siguiente enigma: ¿cuáles discos eran exitosos en su comercialización? El mencionado medio escrito respondió que el público sólo compraba los que reconocía como buenos, así como los que se identificaban con ellos:

"Hay radios que tocan durante todo el día no más de unos treinta títulos. Todos los días a la misma hora, los mismos discos. Son [...] tocadiscos gratuitos y lógicamente, nadie quiere comprar esos discos, porque basta sintonizar la radio y allí están. Hay otras radios, que se esmeran por tocar exclusividades. Son iguales a las otras con la diferencia que si algún zoquete quiere comprar el disco, no puede. Finalmente, existe la radio que toca de todo lo que le llega, lo que tiene desde hace meses y lo que guarda como reliquia desde hace siglos. Esta última, no le hace un favor a nadie, salvo al auditor que por fin descansa de las dos radios anteriores. Con todo eso: ¿qué discos se venden? Simple: los que el público reconoce como buenos y punto. Ya pueden ponerse ñatos los que trabajan en este asunto haciendo tocar discos o tratando de vendérselos a los distribuidores. La verdad, es que solamente se venden -en forma interesante- aquellos discos que se identifican con el público y que éste reconoce como buenos. Todo lo demás, es promoción personal para los que hacen tocar los discos y nada más. Al final, las cifras de ventas hablan claro”. (El Musiquero. No. 32, agosto de 1966: 4).

El fallecido locutor, Carlos Alfonso Hidalgo, expuso en la crónica de Ecran, ¿Cuál es la labor del discjockey?, que la escasa difusión de los artistas chilenos sería provocada por las malas posturas administrativas de los propios dueños de casas discográficas que provocaron la saturación de contratos de grabación. Vale decir, acusó a los propios sellos disqueros de publicar mucho material fonográfico:

"En este sentido, el disc-jockey cumple una tarea seleccionadora, sobretodo, si se le considera la gran cantidad de artistas que graban en la actualidad. El exceso de cantantes, precisamente, por la falta de selección que predomina a veces en los sellos grabadores, y el momento inoportuno en que los lanza o el repertorio inapropiado que les asignan determinan que muchos artistas promisorios pierdan $^{22}$. [Hay buenos elementos] que todavía no han sido explotados con los temas que les corresponden ${ }^{23}$ “. (Hidalgo, Ecran. No. 1756, 22 de septiembre de 1964: 28).

Estas afirmaciones que resumen la absoluta responsabilidad de los propietarios de casas discográficas sobre la propagación de la música nacional, nos llevan por conclusión que esta justificación estuvo fuera y muy lejos de la realidad. ¿El motivo? La última decisión de la difusión radial, en Chile, seguía pasando por los propios disc-jockeys y programadores, 
pese a que "hombres de radio” como Cucho Fernández sostenían, irónicamente, que:

"al público hay que darle lo que pide“. (Cucho Fernández, Ecran. No. 1776, 9 de febrero de 1965: 40).

Dado lo anterior, ¿ ¿la repetición de treinta temas musicales, al día, se debió a un real "negocio escandaloso" entre programadores, disc-jockeys y casas discográficas? El "negocio poco ético" se produjo cuando algunos disc-jockeys ocuparon la política de la payola ${ }^{24}$, provocando que sólo las grandes compañías ocuparan este sistema en desmedro de los pequeños sellos discográficos que no tuvieron recursos monetarios para negociar con los programas radiales. No obstante, disc-jockeys como Agustín Cucho Fernández se defendieron, alegando que la falta de difusión se producía por otra situación: la abultada cantidad de registros comerciales que salían publicados, semana a semana, en nuestro país. De esta manera, sostuvo que la referida práctica de los sellos discográficos criollos era considerada una política muy exagerada para las necesidades de un mercado social pequeño. Esta crítica, muy fundamentada, por cierto, ocasionó que el problema enunciado respondiera a una mera política empresarial improvisada:

"Creo que la cantidad de discos es exagerada. Me parece que la política actual de publicación de grabaciones hace innecesaria la labor del director artístico. Se publica cualquier cosa para ver si le apuntan“. (Cucho Fernández, Ecran. No. 1776, 9 de febrero de 1965: 40).

Del mismo modo, Cucho Fernández expuso que uno de los grandes defectos de las casas disqueras, en Chile, fue tratar de incitar, a sus respectivos intérpretes, a efectuar el primer paso erróneo: grabar un disco, previo a los ensayos y a las presentaciones en directo. Por tal razón, justificó que el disco debía ser el resultado persistente de presentaciones del artista ante el público:

"El disco debe ser el resultado de un trabajo consciente de preparación y selección. Antes del disco debe estar el perfeccionamiento y la labor sacrificada y el estudio paciente, constante. El disco no es un ensayo. Es el resultado de meses largos de trabajo. Llegar al disco debe merecer más respeto. Es lo definitivo ${ }^{25}$ ". (Cucho Fernández, Ecran. No. 1776, 9 de febrero de 1965: 40).

Gutiérrez compartió los dichos con Cucho Fernández frente al rechazo de las improvisadas políticas de registros fonográficos que estaban aplicando las compañías discográficas criollas con sus artistas. Gutiérrez consideró que era muy necesario que los mencionados intérpretes tuvieran una experiencia frente al público, pues estimó que la grabación de un disco no garantizaba la calidad del artista en vivo:

"Este sistema no puede ser bueno. Al disco se debe llegar después de presentaciones personales que aseguren calidad, porque una gra- 
bación presenta al artista con recursos técnicos que lo hacen aparecer muy superior a lo que en realidad es”. (Gutiérrez, Ecran. No. 1776, 9 de febrero de 1965: 41).

García, asimismo, expuso su argumentación, tan similar a las otras anteriores, manifestando que el registro de un disco, no debería ser el fin último para aquellos inexpertos intérpretes criollos, sino, más bien, el medio para desarrollar sus carreras artísticas. El extinto locutor añadió que ya era frecuente que un artista chileno lograra alcanzar una buena impresión, ante el auditor, luego de plasmar su primera placa. No obstante, en muchos casos, las carreras decaían, cuando no podían confirmar su calidad en sus posteriores presentaciones, en directo. Nuevamente, aquí vemos cómo los sellos disqueros nacionales comenzaban a tener la intención de querer probar contratando a los artistas, antes de "foguearlos":

\begin{abstract}
"Se da la sensación de que grabar un disco es el objetivo de un artista, cuando es sólo un medio. Creo que se ha creado un mito en torno al éxito. Muchas veces un artista consigue un verdadero impacto con su primer disco, pero después en sus actuaciones personales, defrauda ${ }^{26}$ ". (García, Ecran, No. 1776, 9 de febrero de 1965: 41).
\end{abstract}

Por otro lado, frente a las exitosas melodías que la industria musical extranjera había publicado, desde antes de 1967, trajo por consecuencia que programadores y disc-jockeys los publicitaran en mayor cantidad que las criollas. En vista de lo enunciado, El Musiquero, en su artículo, Hablemos de Directores Artísticos, no podía comprender cómo, en Chile, no había artistas de peso y de grandes canciones que pudiera contrarrestar al vendaval de música foránea. Por ende, culpó a los directores artísticos cuando contrataron a malos intérpretes que sólo se valieron de un éxito y que, a la postre, desaparecieron rápidamente:

"En nuestro medio, desgraciadamente, la pésima labor realizada por algunos seudos directores artísticos, ha conseguido terminar con el semillero de artistas que siempre existió. Se grabó cualquier cosa, se levantó a cualquier artista y una promoción desorganizada e inútil, consiguió apenas, una popularidad rapidísima para algunos intérpretes, que ya han visto terminada su 'carrera"”. (El Musiquero. No. 44, julio de 1967: 3).

Dado lo anterior, quedaba la interrogante del por qué dichos directores artísticos no tuvieron mayor competencia al saber elegir, difundir e invertir en verdaderos artistas, si desde siempre, en nuestro país, hubo muy "buenos semilleros".

\title{
Conclusión
}

En primer lugar, nunca antes, en la historia de la música grabada criolla $^{27}$, hubo tantos artistas que tuvieron la oportunidad de plasmar, por 
lo menos, un single para una casa discográfica. La cantidad de sellos discográficos, grandes y pequeños, generó que no hubiera mercado para la venta de tantos discos. El problema creció, aún, más cuando los programadores y disc-jockeys decidieron, según su objetividad; y, en otros, por mero "negocio" (payola); qué intérpretes merecían ser difundidos en sus emisoras radiales. La situación no discriminó ninguna tendencia y fue similar para la Nueva Ola, Beat Chileno y Beat Progresivo-Psicodélico Chileno, Neo Folklore, Nueva Canción Chilena, así como para otras corrientes musicales.

En segundo punto, los pequeños sellos disqueros se vieron perjudicados ante las grandes compañías, cuando, evidentemente, no pudieron equilibrar la inversión que apostaron para sus artistas y que se vio reflejada en la citada "simpatía", o bien, inclinación que un disc-jockey podía tener sobre ciertos intérpretes. A fin de cuentas, lo enunciado se convirtió en un conflicto mediático que generó la siguiente dicotomía: artistas "difundidos" / artistas "silenciados". Obviamente, frente a este episodio, las casas disqueras fueron las, mayormente, involucradas debido a que su situación económica dependió de los gustos de los disc-jockeys y programadores de la época.

Por otro lado, ciertas veces la industria discográfica criolla invirtió, económicamente, en obras conceptuales, dando pie para que algunos empresarios protegieran a ciertas producciones nacionales, sobretodo, cuando constituyeron novedad, o bien, cierto valor creativo. Aquello explica, entonces, el esfuerzo económico que representó para casas disqueras como RCA Víctor, la publicación de obras musicales como Al $7^{\circ}$ de Línea (1966) de Los Cuatro Cuartos, o bien, Kaleidoscope Men (1967) de Los Mac's. La anterior producción, gloriosa obra del Neo Folklore, significó exportar un long play que sintetiza un hecho histórico nacional-internacional como la Guerra del Pacífico, en tanto, la última, magnánima producción del Beat Progresivo-Psicodélico Chileno, registra la vanguardia y novedad por medio de efectos especiales y extraños dentro de una base rockera.

Finalmente, con todos los antecedentes mencionados se traza una parte de la historia de la música grabada chilena durante el período 19641967. 


\section{Notas}

${ }^{1}$ Por medio de la forma colectiva de sus trabajadores, de la posesión de un capital y de una tecnología que convierte en producto los bienes y servicios, la industria toma vínculo con los consumidores y potencializa su mercado. El sociólogo, José Joaquín Brunner, en su publicación, Cartografías de la modernidad, profundiza que: “[Los mismos mercados coordinan el intercambio] entre productores y consumidores, a través de un sistema de precios determinado mediante la oferta y la demanda de bienes y servicios. Forman un orden espontáneo y anónimo de interacciones”. (Brunner 1995: 78).

${ }^{2}$ La autora cita a Franco Rositi en Historia y teoría de la cultura de masas (1980), Ediciones Gustavo Gili, Barcelona, España 1980. p. 36.

${ }^{3}$ Para comprender, aún, más el mecanismo de la industria musical, leer Transformaciones de la industria musical de Anny Rivera (1984), Músicos sin pasado de Roberto Escobar (1971) y La Historia Social de la Música Popular en Chile (1890-1950) de Juan Pablo González y Claudio Rolle (2005).

${ }^{4}$ González y Rolle agregan que estas últimas características son las que originan diferencias entre la industria del disco y la radio dentro del consumo cultural, puesto que el registro fonográfico "permite la reproducción musical a voluntad, disminuyendo así mismo su interés inicial como receptor y transmisor de la voz hablada”. (González y Rolle 2005: 174).

${ }^{5}$ Para conocer más el rol de la radio en las sociedades modernas, leer Hacia una nueva comprensión del mundo juvenil de Rodrigo Andrade y Óscar Aguilera (1998).

${ }^{6}$ Ecran publicó el reportaje, Cuatro caras para un mismo disco, para presentar declaraciones de locutores como Julio Gutiérrez, quien manifestó acerca del valor que el disc-jockey le había entregado a la canción grabada: "El disc-jockey le dio al disco su verdadero valor, contribuyendo con la difusión a [la superación] de los artistas y encauzando el gusto de la mayoría del público”. (Gutiérrez, Ecran. No. 1776, 9 de febrero de 1965: 41).

${ }^{7}$ En 1965, el extinto locutor, Julio Gutiérrez, había admitido que las escasas ventas de los discos apuntaban a la baja calidad de algunos intérpretes que no merecían plasmar un registro fonográfico (Ecran. No. 1776, 9 de febrero de 1965: 41).

${ }^{8}$ Waldo Morales nos declara su impresión sobre la problemática expuesta por los discjockeys frente a qué intérpretes nacionales merecían registrar un disco. Para el ex-vocalista y guitarrista rítmico de Los Sicodélicos, el comienzo de una carrera musical significaba no sólo “aparecer”, sino que también “permanecer”. No obstante, no todas las casas discográficas comprendieron alcanzar la madurez o consagración de un intérprete. En definitiva, el citado músico nos asegura que, en la historia de la música popular criolla, hubo muchos artistas que sólo se valieron de un éxito radial: "La producción discográfica, en Chile, era muy acelerada, a mediados de los años '60, a diferencia de hoy en día. Asimismo, en nuestro país, grabar un disco, era la máxima aspiración que podía aspirar un artista, en aquella época. Sin embargo, en la carrera musical no sólo se trata de 'aparecer', sino, más bien, 'aparecer' y 'permanecer'. Es muy fácil ‘aparecer' y eso nos podría llevar toda una noche de gente que ‘apareció’, pero que estuvo sólo un día” (Morales, 6 de octubre de 2006).

${ }^{9}$ El desaparecido disc-jockey, Ricardo García, indicó que frente a la misma problemática de la publicación semanal de discos, en Chile, no era un buen momento para efectuarlo. Sin embargo, agregó que aquellas decisiones de las casas disqueras respondían a políticas muy 
complicadas: "En estos momentos, NO, pero los sistemas de trabajo de las grandes empresas son muy complejos“. (García, Ecran, No. 1776, 9 de febrero de 1965: 40).

${ }^{10}$ En cuanto al conflicto de las bajas ventas de discos, hombres de radio como Miguel Davagnino justificaron que dicha problemática fue atribuida a su pujante alza de precios (Ecran. No. 1776, 9 de febrero de 1965: 41).

\section{${ }^{11}$ Para profundizar más, leer El Beat Chileno, El Beat Progresivo-Psicodélico Chileno y Los Sicodélicos (1964-1968) Gajardo Cornejo (2009).}

${ }^{12}$ Otra gran producción fue, sin lugar a dudas, Sicodelirium que Los Sicodélicos grabaron para el Sello ORPAL, en 1967. Dicho larga duración se le reconoce por ser el primero en la historia de la música popular grabada chilena que produjo un hibridismo timbrístico-musical cuando entrelazó instrumentos autóctonos y mapuches dentro de una base musical beatpsicodélica. En este contexto, el esfuerzo financiero de inversión de parte de su casa discográfica se tornó en el riesgo que significó no contar con el impacto de venta que se esperó del aludido long play. Para mayor estudio de este caso, leer Sólo tu nombre puede cortar las flores: La biografía de Los Sicodélicos (Gajardo Cornejo 2010).

${ }^{13}$ El extinto locutor, Cucho Fernández, pronunció que los programas de disc-jockeys, comercialmente, han difundido la aparición de nuevos artistas y lo consideró como un número completo en la programación radial. (Cucho Fernández, Ecran. No. 1776, 9 de febrero de 1965: 40).

${ }^{14}$ Davagnino, en tanto, profundizó que los programas que conducían los disc-jockeys debían cumplir la función de informar y entretener, pero para una juventud que también aprendiera a elevar su nivel cultural. (Davagnino, Ecran. No. 1776, 9 de febrero de 1965: 41).

${ }^{15}$ El periodista, Gonzalo Planet, en su publicación, Se oyen los pasos, señala que la radio constituyó un pilar fundamental para la transmisión de registros discográficos de los artistas y que personajes como Fernández condujeron espacios como El show efervescente de Yastá, en Radio Corporación, para programar, incansablemente, los mismos discos durante la emisión radial. ¿A razón de qué? A razón de que el público los memorizara (Planet 2004: 21).

${ }^{16}$ Uno de aquellos ejemplos es, sin lugar a dudas, Hugo Ortega.

${ }^{17}$ Davagnino, explicó que frente a sus selecciones de discos, él mismo buscaba las mejores grabaciones de acuerdo a cada intérprete y al gusto del auditor chileno. (Davagnino, Ecran. No. 1776, 9 de febrero de 1965: 41).

${ }^{18}$ García, por su parte, tomaba una postura bien arriesgada que se inclinaba a la buena calidad de la grabación en desmedro de una posible baja de sintonía. Este desaparecido disc-jockey admite que seleccionaba los temas musicales con: "sentido común, respeto por el auditor y criterio para comprender que es preferible perder dos puntos de sintonía a cambio de calidad. Esa es nuestra responsabilidad“. (García, Ecran. No. 1776, 9 de febrero de 1965: 40).

${ }^{19}$ Gutiérrez explica, en tanto, que las veces que escuchaba una determinada canción era bajo distintos estados emocionales lo que, en definitiva, decidía su selección y decisión adecuada: "Las escucho calmadamente tres o cuatro veces y así puedo apreciarlas bajo 
distintos estados anímicos“. (Gutiérrez, Ecran. No. 1776, 9 de febrero de 1965: 41).

${ }^{20}$ Gutiérrez añadió que la excesiva difusión radial de los discos ocasionaba que pasaran, inmediatamente, de moda, antes de adquirirlos (Ecran. No. 1776, 9 de febrero de 1965: 41).

${ }^{21}$ Carlos Alfonso Hidalgo señaló que el rol específico del disc-jockey estuvo más dirigido más al público que al propio artista. (Hidalgo, Ecran. No. 1756, 22 de septiembre de 1964: 28).

${ }^{22}$ Morales agrega: "Si tú revisas la historia musical de los últimos 40 años existen casos en que grupos musicales le apuntaron a un sólo éxito. En definitiva, lo que los locutores de la época hablaban era la de una realidad de todos los días”. (Morales, 6 de octubre de 2006).

${ }^{23}$ Comentarios como el de Davagnino colaboraron con la dura crítica que resolvió Hidalgo contra las compañías disqueras cuando declaró que: "Los sellos grabadores deberían preocuparse más de la calidad que de la cantidad“. (Davagnino, Ecran. No. 1776, 9 de febrero de 1965: 41).

${ }^{24}$ Trato o negocio informal entre el artista y el disc-jockey y/o programador radial que se efectúa mediante un pago por una cierta cantidad de veces que se difunde un disco. En Estados Unidos, en los años '50, el famoso locutor, Alan Freed, fue acusado de efectuar la payola y, por ende, recibió muchas críticas y acusaciones de los medios escritos. ¿La razón? Públicamente, era un hecho catalogado de muy poco ético.

${ }^{25}$ Para profundizar más la citada problemática, leer El Beat Chileno, El Beat ProgresivoPsicodélico Chileno y Los Sicodélicos (1964-1968) Gajardo Cornejo (2009: 104-117).

${ }^{26}$ Más preciso que Cucho Fernández, García y Gutiérrez resultó ser Davagnino, quien emitió que cualquier sujeto podía plasmar una pieza musical, pero, finalmente, la decisión de la promoción, pasaba por las manos del disc-jockey: "Cualquier sistema honrado es bueno para que un artista inicie su carrera. Si tiene calidad, triunfará, es lógico. Allí entra la labor del disc-jockey de seleccionar lo mejor“. (Davagnino, Ecran. No. 1776, 9 de febrero de 1965: 41).

${ }^{27}$ Y quizás nunca después... 


\section{Bibliografía}

Aguilera, O; Andrade, R. (1998), Hacia una nueva comprensión del mundo juvenil. Centro de Investigaciones Sociales de la Universidad Arcis, Santiago de Chile.

Brunner, J. J. (1995), Cartografías de la modernidad. Dolmen, Santiago de Chile.

Cave (1965), ."Hablemos de... discos a menor costo”, El Musiquero. No. 10, enero de 1965. Lord Cochrane. Santiago de Chile. pp. 3.

Ecran (1964), “Todas las emisoras se parecen, ¿Por qué?” No. 1740, 2 de junio de 1964. Zig-Zag, Santiago de Chile. pp. 5

Ídem (1964), “¿Cuál es la labor del discjockey?”, No. 1756, 22 de septiembre de 1964. Zig-Zag, Santiago de Chile. pp. 28

Ídem (1965), “Cuatro caras de un mismo disco”. No. 1776, 9 de febrero de 1965. Zig -Zag, Santiago de Chile. pp. 40-42

Ídem (1968), “Peligro Radioactividad”. No.1967. 5 de noviembre de 1968. Zig-Zag, Santiago de Chile. pp. 31

El Musiquero (1964), “Editorial”, No. 5, agosto de 1964. Lord Cochrane, Santiago de Chile. pp. 3

Ídem (1965), “Hablemos de ...”, No. 20, 1ª Quincena de agosto de1965. Lord Cochrane, Santiago de Chile. pp.3

Ídem (1966), “Sin Carátula”, No. 32, agosto de 1966. Lord Cochrane, Santiago de Chile. pp.4

Ídem (1966), “Sin Carátula”, No. 34, octubre de 1966. Lord Cochrane, Santiago de Chile. pp.4

Ídem (1967), “Hablemos de los sellos particulares”, No. 44, julio de 1967. Lord Cochrane, Santiago de Chile. pp. 3

Ídem (1967), "Hablemos de los sellos particulares”, No. 45, agosto de 1967. Lord Cochrane, Santiago de Chile pp. 7

(Ídem, 1967), “Sin carátula: Los programadores”, No. 47, octubre de 1967. Lord Cochrane, Santiago de Chile. pp. 9

Escobar, R. (1971), Músicos Sin Pasado. Pomaire, Santiago de Chile.

Gajardo Cornejo, Claudio (2009), El Beat Chileno, El Beat ProgresivoPsicodélico Chileno y Los Sicodélicos (1964-1968). Tesis de Magíster en Artes con mención en Musicología. Facultad de Artes, Universidad 
de Chile. Santiago, Chile.

Ídem (2010), Sólo tu nombre puede cortar las flores: La biografía de Los Sicodélicos. Santiago, Chile (Autoproducción).

http://www.slideshare.net/rocketblues1/slo-tu-nombre-puede-cortar-las-flores-la-biografa-de-los-sicodlicos-6130963

González, J.P y Rolle, C. (2005), La Historia Social de la Música Popular en Chile (1890-1950). Ediciones Universidad Cato_lica de Chile. Santiago de Chile.

Gutiérrez Toro, Diana (2003), La Música como Antídoto de la imagen: El caso “Blue”. Tesis de Magíster en Artes, mención en Musicología. Facultad de Artes, Universidad de Chile. Santiago, 2003.

Martínez, J. (2000), La década de los '60 y la música de difusión masiva: la Nueva Ola Chilena como sistema cultural. Quilpué, Chile. pp.29 (artículo inédito).

Morin, E y Adorno, T. (1967), La industria cultural. Galerman, Buenos Aires.

Planet, G. (2004), Se oyen los pasos: La historia de los primeros años del rock en Chile. Del beat y la psicodelia al folk rock (1964-1973). Beatguru Libros, Santiago de Chile.

Rivera, A. (1983), Transformaciones culturales y movimiento artístico en el orden autoritario: Chile 1973-1982. CENECA, Santiago de Chile.

Rositi, F. (1980), Historia y teoría de la cultura de masas”. Ediciones Gustavo Gili. Barcelona, España.

Santa Cruz, D. (1950), “Medio siglo” en Revista Musical Chilena VI/ XXXVII (Otoño). Santiago de Chile.

\section{Entrevista}

Morales, Waldo (2006), Ex-vocalista y guitarrista rítmico de Los Sicodélicos, Santiago Centro, 6 de octubre de 2006 y Quilpué, 1 de noviembre de 2006. 